\title{
ANALISIS DESAIN DAN UJI KINERJA STT-MBE BASIS TRAFO
}

\author{
Darsono, Saefurrochman, Rian Suryo Darmawan, Suhartono \\ Pusat Teknologi Akselerator dan Proses Bahan, BATAN \\ J.Babarsari Kotak Pos 6101 Ykbb, Yogyakarta 55281 \\ e-mail : b_darsono@batan.go.id
}

Diterima 22 Mei 2012, diterima dalam bentuk perbaikan 05 Juli 2012, disetujui 06 Juli 2012

\begin{abstract}
ABSTRAK
ANALISIS DESAIN DAN UJI KINERJA STT-MBE BASIS TRAFO. Telah dilakukan analisis desain dan uji kinerja STT-MBE berbasis transformator (trafo) 3 fase untuk menentukan penyebab spesifikasi teknis tidak dicapai pada uji kinerja. Metode analisis dilakukan dari tiga aspek. Pertama analisis dokumen desain dan konstruksi menggunakan standar IEC/SNI dan handbook trafo ABB untuk mengetahui kesesuaian komponen desain. Kedua, simulasi desain trafo menggunakan program VIZIMAG untuk mengetahui kebenaran perhitungan analitik desain. Ketiga, melakukan uji tegangan dadal komponen konstruksi padat dan insulasi oli untuk mengetahui desain keamanan tata letak komponen tegangan tinggi STT. Berdasarkan analisis pertama ternyata hampir 30\% bahan komponen STT tidak memenuhi standar trafo. Dari analisis kedua ternyata perhitungan analitik desain trafo sudah benar. Berdasarkan analisis ketiga ternyata tegangan dadal oli terukur 3 kali lebih kecil dari asumsi desain keamanan, sedangkan struktur fleksiglas bisa digunakan karena mempunyai tegangan dadal $45 \mathrm{kV} / \mathrm{mm}$ dan flashover $60 \mathrm{kV}$ pada jarak $1 \mathrm{~cm}$. Dari hasil review dokumen desain, hasil analisis eksperimen tegangan dadal dan flashover serta dari simulasi analisis desain trafo terungkap bahwa penyebab utama spesifikasi STT-MBE tidak dicapai, karena asumsi angka keamanan desain tata letak komponen STT sebesar 2 kali tegangan dadal oli trafo adalah aman. Berdasarkan analisis ini dapat disimpulkan bahwa trafo tidak dapat dioperasikan sesuai spesifikasi teknis, namun dengan perbaikan tata letak komponen STT di dalam bejana oli diharapkan dapat dioperasikan sampai $260 \mathrm{kV}$.
\end{abstract}

Kata kunci : trafo, STT, analisis desain, kinerja, MBE.

\begin{abstract}
DESIGN ANALYSIS AND PERFORMANCE TEST TRANSFORMER BASED HIGH VOLTAGE SOURCE OF ELECTRON BEAM MACHINE. Design analysis and performance test 3-phase transformer based high voltage source of electron beam machine to determine the technical specification's failure at performance test. The analysis method is divided into three methods. The first method is document analysis and construction using IEC/SNI transformer standardization and ABB transformer handbook to determine the compatibility of the component design. The second method is simulating the transformer design using VIZIMAG software to validate the analytic calculations design. The third method is performing breakdown voltage test on solid component construction and oil insulation to determine the safety design of the high voltage source component's layout. Based on the first analysis, almost $30 \%$ of the high voltage source component's material does not meet transformer standardization. Based on the second analysis, the analytic calculations of transformer design are correct. Based on the third analysis, the measured oil breakdown voltage is three times smaller than the safety design assumption, while the acrylic structure can be used because of its breakdown voltage $45 \mathrm{kV} / \mathrm{mm}$ and flashover $60 \mathrm{kV}$ at a distance of $1 \mathrm{~cm}$. From the document design review, the experimental analysis of the breakdown voltage and flashover as well as the simulated transformer design analysis , revealed that the main causes of electron beam machine high voltage source specifications are not achieved due to determining layout design safety factor of high voltage source's components twice breakdown voltage of oil transformer is safe. Based on this analysis, it can be concluded that the transformer can not be operated according to technical specifications. Nevertheless with improvements in the high voltage source's components layout in the oil vessel, are expexted to be operated up to $260 \mathrm{kV}$.
\end{abstract}

Keywords: transformers, high voltage source, design analysis, performance, electron beam machine.

\section{PENDAHULUAN}

ME (Mesin Berkas Elektron) telah banyak dimanfaatkan sebagai sumber radiasi pada proses iradiasi suatu Wroduk industri. Beberapa industri ban mobil dan kabel telah menggunakan MBE untuk meningkatkan kualitas produknya ${ }^{(1,2,3)}$. Karet alam sebagai bahan baku utama dari industri tersebut sangat berlimpah di Indonesia, sehingga potensi penggunaaan MBE akan semakin besar ${ }^{(4,5)}$. Berdasarkan uraian di atas telah 
dilakukan rancangbangun prototip MBE dengan kapasitas $300 \mathrm{keV/20} \mathrm{mA} \mathrm{untuk} \mathrm{vulkanisasi} \mathrm{iradiasi} \mathrm{lateks} \mathrm{karet}$ alam(6).

Mesin berkas elektron untuk vulkanisasi iradiasi lateks karet alam terdiri dari beberapa komponen utama yang meliputi sumber elektron, sumber tegangan tinggi (STT), tabung akselerator, tabung pemayar dan window (jendela) Ti, sistem optik, sistem vakum, sistem instrumentasi dan kendali, sistem keselamatan radiasi dan ozon, kerangka MBE serta komponen pendukung yang meliputi pengaduk cairan lateks. Salah satu komponen utama MBE yang sangat vital adalah sumber tegangan tinggi.

Sumber tegangan tinggi untuk MBE adalah sumber tegangan tinggi arus searah (DC) yang digunakan untuk mencatu tabung pemercepat MBE. Menurut cara pembangkitan tegangannya terdapat 3 macam jenis sumber tegangan tinggi $\mathrm{DC}^{(7)}$ yaitu: pelipat tegangan (Cockcroft-Walton, Dynamitron), penimbunan muatan (Van de Graaff) dan tipe transformator. Berdasarkan sifat-sifat yang dimiliki jenis Cockcroft-Walton dan Van de Graaff lebih sesuai untuk sumber tegangan dengan kapasitas tegangan yang relatif tinggi (ratusan $\mathrm{kV}$ s/d orde MeV) dengan arus kecil (orde $\mathrm{mA}$ ), sedangkan jenis transformator sesuai untuk tegangan yang relatif lebih rendah $(<500 \mathrm{kV}$ ) dengan arus besar (orde puluhan s/d ratusan $\mathrm{mA}$ ). STT jenis transformator dibedakan menjadi dua yaitu: jenis inti terbumikan (grounded core transformer type atau GCT) dimana antara kumparan primer dan sekunder terinsulasi langsung terhadap tegangan tinggi DC, dan yang lain adalah tipe inti terinsulasi (insulated core transformer type atau ICT) dimana insulasi terhadap tegangan tinggi DC terbagi dalam beberapa tahap sesuai tingkat kumparan sekundernya.

Dalam rancangbangun prototip MBE $300 \mathrm{keV} / 20 \mathrm{~mA}$ digunakan STT MBE basis transformator dari jenis inti terbumikan (GCT) karena kesederhanaan konstruksinya, dan efisiensi konversi daya tinggi dibandingkan dengan jenis ICT(8). Dalam hal ini transformator yang digunakan adalah dari konfigurasi 3 fase, tegangan sekunder dari masing-masing fase diubah menjadi tegangan tinggi DC menggunakan rangkaian pengganda tegangan yang tersusun atas komponen dioda dan kapasitor tegangan tinggi. Keluaran tegangan tinggi DC dari masing-masing fase kemudian saling dihubungkan secara seri untuk memperoleh keluaran tegangan tinggi yang diinginkan. Insulasi tegangan tinggi yang digunakan pada STT MBE basis trafo ini menggunakan oli new Diala B, sedangkan komponen struktur konstruksi menggunakan fleksiglas dan PVC. Adapun skema konfigurasi STT seperti ditunjukkan pada Gambar 1.

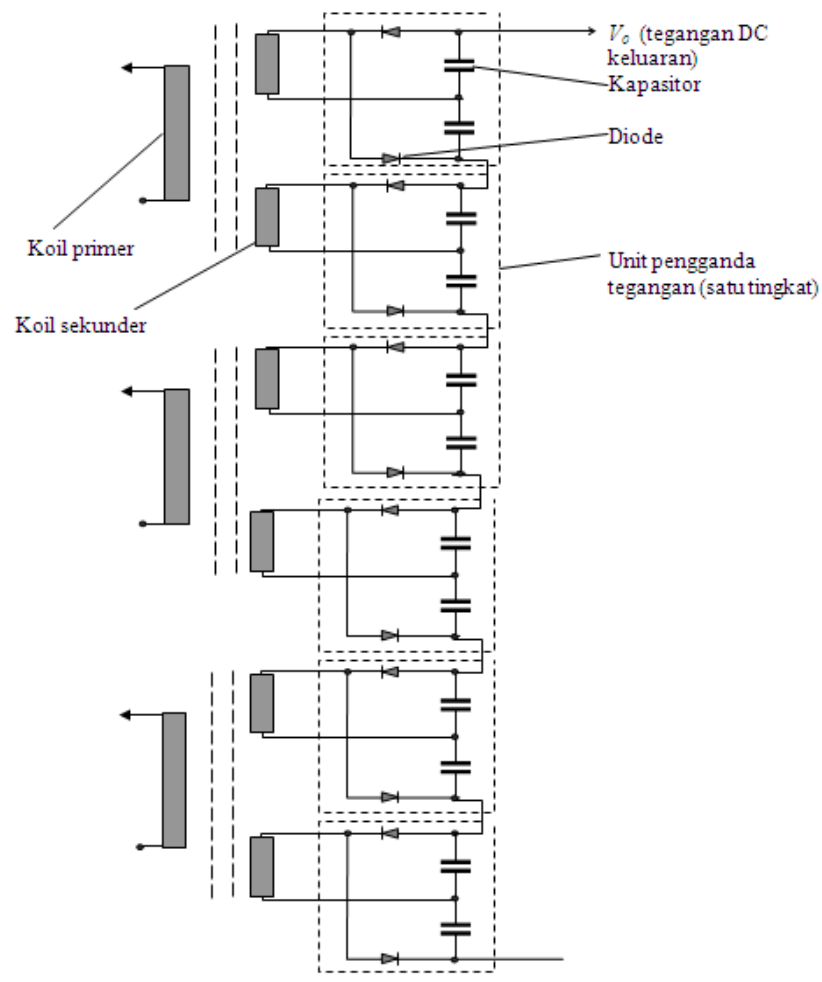

Gambar 1. Skema konfigurasi rangkaian STT.

Sumber tegangan tinggi ini sudah berhasil dikonstruksi dan diuji kinerjanya pada keadaan tanpa beban. Hasil uji kinerja STT menunjukkan hanya mampu memberikan tegangan keluaran $148 \mathrm{kV}$ pada keadaan oli tanpa 
purifikasi dan $186 \mathrm{kV}$ pada keadaan oli dipurifikasi, di atas tegangan ini terjadi lucutan listrik di dalam bejana STT. Sebagai akibatnya komisioning awal MBE tahun 2010 tidak dapat terlaksana dikarenakan STT tidak mencapai spesifikasi minimum yang diinginkan minimal $200 \mathrm{kV}$. Padahal investasi untuk litbang ini cukup besar $(>1 \mathrm{M})$ sehingga perlu diteliti dan dianalisis penyebab spesifikasi minimum STT tidak tercapai dari aspek desain (material, perhitungan detail, dan tata letak) dan hasil uji kinerja STT(9). Tujuan penelitian ini ialah melakukan analisis tidak tercapainya spesifikasi teknis STT-MBE basis trafo. Metode analisis dilakukan dari tiga aspek yaitu: pertama analisis dokumen desain dan konstruksi, menggunakan standar trafo $|\mathrm{EC} / \mathrm{SNN}|^{\left({ }^{10}\right)}$, dan handbook trafo $\mathrm{ABB}{ }^{(11)}$ untuk mengetahui kesesuaian komponen desain, kedua simulasi desain trafo menggunakan program VIZIMAG(12) untuk mengetahui kebenaran perhitungan analitik desain, ketiga melakukan uji tegangan dadal komponen konstruksi padat dan insulasi oli untuk mengetahui desain keamanan tata letak komponen tegangan tinggi STT. Data hasil analisis STT sangat penting untuk pengembangan teknologi STT selanjutnya baik berbasis trafo dengan oli atau gas.

\section{METODOLOGI}

\section{Alat dan Bahan}

Alat dan bahan yang digunakan ialah oil tester, multimeter, STT Cockcroft Walton, komputer, alat uji tegangan dadal (breakdown voltage) dan (lewat denyar) flashover, oli, fleksiglas, program Vizimag, dokumen detail desain STT-MBE basis trafo, dokumen standar trafo IEC/SNI(10), dan Handbook trafo ABB(11).

\section{Uji Insulasi Oli Trafo}

Uji insulasi oli trafo STT dilakukan menggunakan oil tester merk CG Mechanical \& Electrical Equipment Co.Ltd. Elektroda yang digunakan dalam pengujian insulasi oli adalah bentuk setengah bola. Elektroda ini banyak digunakan pada pengujian insulasi bahan cair maupun udara. Dua elektroda setengah bola terbuat dari bahan tembaga dengan jarak antar elektroda dapat diatur. Pada ujung elektroda disuplai tegangan tinggi DC dengan skema pengujian seperti ditunjukkan pada Gambar 2. Dengan menaikkan tegangan DC secara perlahan maka tegangan dadal pada jarak tertentu dapat diamati dengan adanya loncatan listrik antara dua elektroda yang secara otomatis alat uji ini akan mematikan tegangan terpasang pada elektroda.

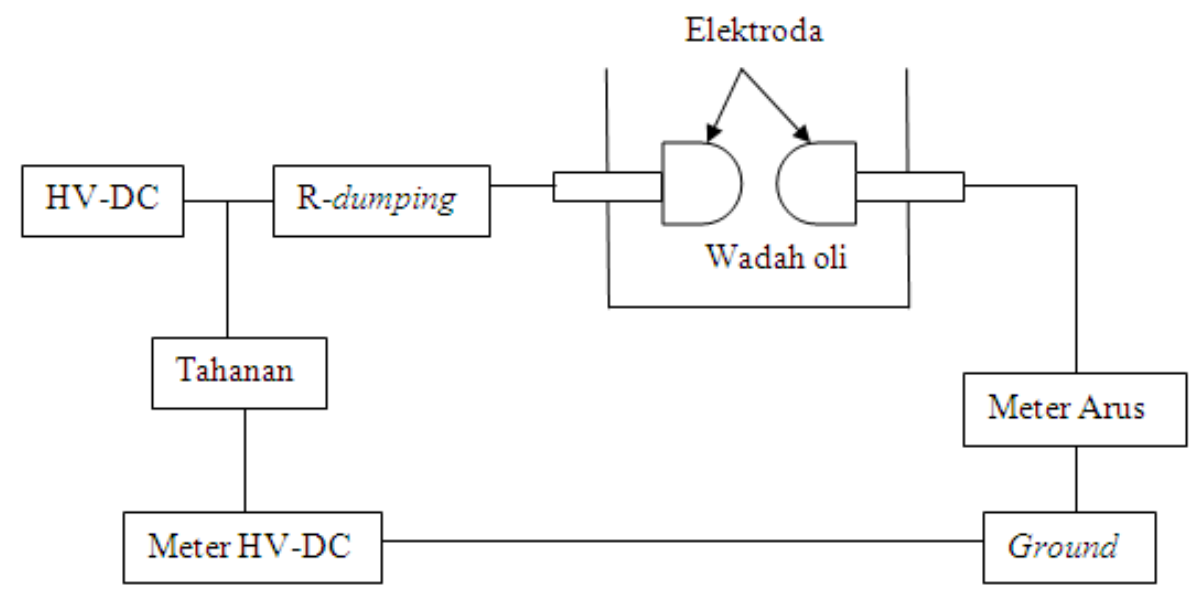

Gambar 2. Skema pengujian insulasi oli trafo STT.

Oli yang akan diuji dimasukkan pada bejana sampai kedua elektroda di dalam bejana terendam, kemudian dilakukan pengamatan tegangan insulasi dengan memberi suplai tegangan tinggi DC pada elektroda untuk berbagai variasi jarak antar elektroda.

\section{Uji Tegangan Dadal dan Flashover Fleksiglas}

Pada pengujian ini digunakan elektroda jarum-jarum berdasarkan standar uji IEC 1109. Dalam hal pengujian tegangan dadal, sampel fleksiglas ukuran $20 \times 20 \times 5 \mathrm{~cm}$ yang akan diuji dijepit diantara dua elektroda jarum. Pada pengujian flashover dua jarum ditempatkan pada permukaan sampel pada jarak tertentu. Skema pengujian dapat dilihat pada Gambar 3. Suhu ruangan dan kelembaban diatur sampai mencapai $20{ }^{\circ} \mathrm{C}$ dan $70 \%$. Kemudian tegangan tinggi (HV-DC) berasal dari generator Cockcroft Walton diterapkan pada dua jarum elektroda. 
Selanjutnya tegangan DC dinaikkan secara bertahap dan ditahan sampai 1 menit tiap kenaikan tegangan sampai terjadi tegangan tembus listrik ditunjukkan untuk uji tegangan dadal, sedangkan untuk uji flashover sampai terjadi loncatan listrik antara elektroda melalui permukaan sampel. Indikasi terjadinya kedua peristiwa ini dapat diamati dengan adanya kenaikan arus yang sangat besar pada multimeter.

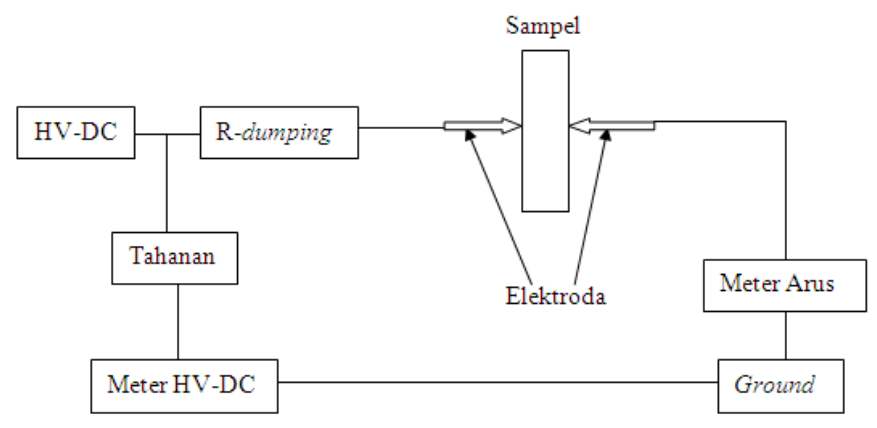

Gambar 3a. Skema pengujian tegangan dadal fleksiglas.

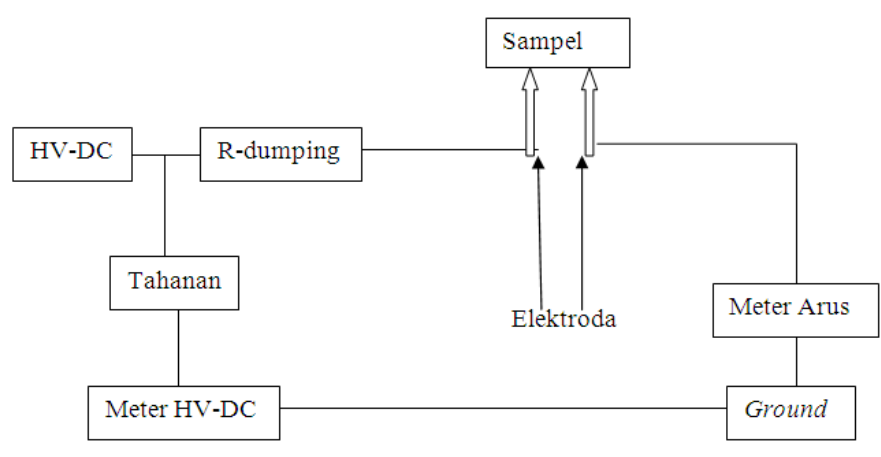

Gambar 3b. Skema pengujian flashover fleksiglas.

\section{Review Dokumen Desain dan Konstruksi Desain STT}

Dokumen desain STT, baik desain dasar dan desain detail tersedia untuk di-review, namun dokumen konstruksi tidak ada. Oleh karena itu dilakukan pemotretan riil dari komponen STT dan menanyakan ke teknisi yang membuat komponen tersebut. Review dokumen mengacu pada standar trafo IEC/SNI(10), dan handbook trafo $A B B^{(11)}$ (pabrik trafo di Amerika). Fokus review pada bahan yang digunakan dalam pembuatan STT basis trafo baik bahan utama, bahan struktrur dan bahan dukung.

\section{Simulasi Desain Trafo Menggunakan VIZIMAG}

Simulasi desain trafo dilakukan menggunakan program Vizimag yaitu suatu program desain trafo berdasarkan metode FEM (Finite Element Method). Program ini tidak hanya menghasilkan output tegangan tetapi juga memberikan informasi efisiensi daya, daya ke beban (power to load), daya lilitan (winding power), reaktansi dan resistansi efektif, induktansi, induktansi saling (mutual inductance), koefisien gandengan (coupling coefficient) serta kontur densitas fluks magnet. Untuk menganalisis desain trafo harus dibuat terlebih dahulu model trafo menggunakan Vizimag dengan masukkan dimensi penampang magnet sebagai inti trafo beserta permeabilitasnya, jumlah lilitan primer dan sekunder serta arus pada primer, resistansi primer dan sekunder, tahanan beban sekunder, frekuensi dan tegangan primer. Program Vizimag dilengkapi dengan analisis trafo secara manual dan model. Untuk mendapatkan hasil yang lebih akurat, maka pertama dilakukan analisis trafo secara model, kemudian dilakukan analisis trafo secara manual. Dengan modus manual bisa memasukkan parameter induktansi lilitan primer dan sekunder serta koefisiensi gandengan. Adapun diagram alir dari simulasi trafo menggunakan Vizimag terlihat pada Gambar 4.

Langkah-langkah dalam membuat simulasi trafo menggunakan Vizimag meliputi:

\section{Start/Mulai}

Tekan ikon Vizimag, maka interface window Vizimag akan tertampil. Perintah operasi program ada pada bagian atas dalam bentuk huruf dan perintah ini diwakili oleh perintah bentuk ikon pada bagian kanan interface 
window. Ada 4 kelompok perintah bentuk ikon yaitu perintah I (File, View, Analyze), perintah II (Add magnetic region), perintah III (Add flux sources), perintah IV (Edit). Bagian kiri interface window adalah layar grid simulasi untuk pembuatan model.

\section{Pembuatan Model}

Model trafo dibuat dengan perintah II dan III dengan cara menggambar bentuk inti trafo menggunakan perintah II. Kemudian lilitan selonoida diberikan pada inti sesuai yang dengan desain yang diinginkan. Pada saat melakukan perintah II dan III diperlukan data dimensi inti trafo, permeabilitas bahan, jumlah lilitan primer dan sekunder, serta arus yang mengalir pada lilitan pada primer. Jika ada kesalahan dalam pembuatan model dapat diperbaiki dengan perintah IV.

\section{Runing Garis Gaya Magnet}

Setelah model trafo sesuai yang diinginkan kemudian tekan ikon Run (gambar lingkaran) untuk membentuk garis gaya magnet.

\section{Runing Trafo Analisis}

Dengan menekan ikon gambar trafo maka dapat dilakukan analisis secara Model dan Manual. Analisis secara Model dengan meng-klik lilitan primer dan sekunder kemudian memasukan tegangan, jumlah lilitan dan tahanan primer, jumlah lilitan dan tahanan sekunder serta frekuensi dan tahanan beban trafo selanjutnya klik ikon Calculate.

\section{Hasil Analisis}

Setelah menekan ikon Calculate dan menunggu beberapa menit tergantung kompleksitas desain, kemudian hasil simulasi disan trafo akan diperoleh. Jika hasil simulasi belum memuaskan khususnya parameter trafo seperti induktansi dan koefisien gandengan belum sesuai yang diinginkan, maka dapat dilakukan analisis secara manual.

\section{Selesai}

Setelah hasil simulasi telah memuaskan, maka program dapat dihentikan dengan menekan ikon Stop.

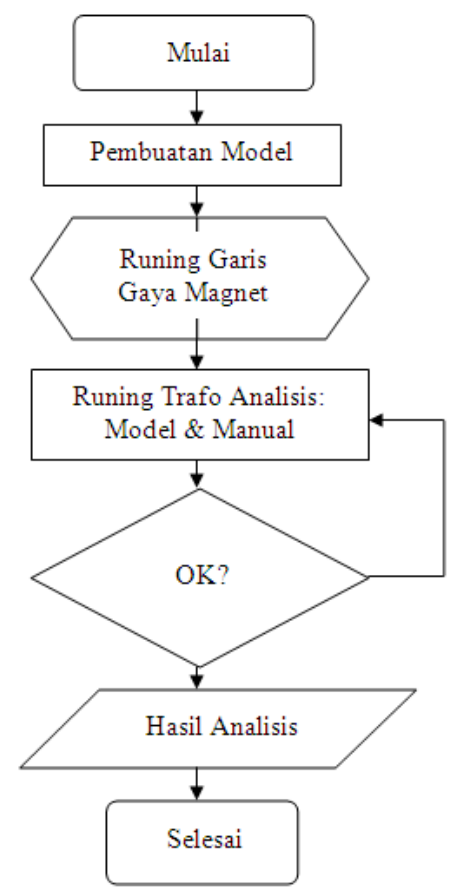

Gambar 4. Diagram alir simulasi trafo menggunakan Vizimag.

\section{HASIL DAN PEMBAHASAN}

\section{Uji Insulasi Oli Trafo}

Untuk menganalisis tidak tercapainya spesifikasi teknis STT basis trafo dikarenakan adanya tegangan dadal antara body STT dan sumber potensial tegangan tinggi, maka dilakukan uji insulasi oli trafo. Hasil uji tegangan 
dadal oli trafo terlihat pada Gambar 5. Pada pengujian ini oli trafo diambil dari bejana STT, kemudian dilakukan pengujian untuk berbagai jarak elektroda menggunakan oli tester buatan Cina merk CG Mechanical \& Electrical Equipment Co.Ltd. Pengambilan data percobaan untuk jarak elektroda tertentu dilakukan pengamatan lima kali yaitu dengan cara mengulang pengukuran tegangan dadal. Untuk menjamin bahwa oli yang diuji tidak rusak (mempunyai kondisi yang sama), maka setiap pengambilan data percobaan untuk jarak elektroda tertentu menggunakan oli baru dari bejana STT. Dari data percobaan jarak elektroda fungsi tegangan dadal kemudian dilakukan pencocokan data menggunakan program Excel. Dari Gambar 3 terlihat bahwa kenaikan tegangan dadal oli trafo STT-MBE tidak linier terhadap jarak elektroda, pada jarak $5 \mathrm{~cm}$ tegangan dadalnya adalah $200 \mathrm{kV}$. Di dalam desain STT basis trafo diasumsikan bahwa tegangan dadal oli adalah $75 \mathrm{kV} / \mathrm{cm}$ (dengan angka keamanan 2 kali) jadi untuk jarak $5 \mathrm{~cm}$ seharusnya mampu menahan tegangan tinggi $375 \mathrm{kV}$. Angka keamanan 2 bisa digunakan jika menggunakan oli standar tegangan tinggi, faktanya untuk oli Diala B yang digunakan hanya mampu $40 \mathrm{kV} / \mathrm{cm}$. Inilah penyebab utama spesifikasi STT-MBE tidak tercapai. Tegangan dadal pada oli diduga awalnya diakibatkan adanya gerakan partikel pengotor oli dengan adanya tegangan tinggi DC, kemudian partikel tersebut menjadi penghubung dengan bodi trafo. Hal ini diamati pula oleh R. Sarathi, A.J. Reid, dan M.D. Judd(13) pada penelitiannya berjudul studi lucutan parsial pada tranformator oli dikarenakan gerakan partikel di bawah pengaruh tegangan tinggi DC menggunakan UHV. Apabila partikel pengotor oli tersebut berupa partikel magnetik ternyata dapat meningkatkan kuat dadal dielektrik sebagaimana diamati oleh Peter Kopčanský dkk ${ }^{(14)}$.

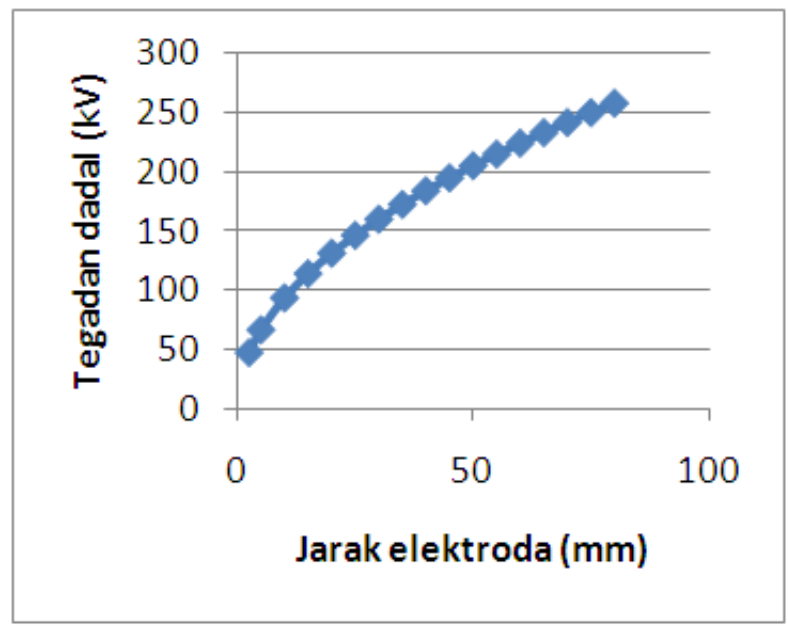

Gambar 5. Karakteristik tegangan dadal oli trafo STT-MBE.

\section{Uji Tegangan Dadal dan Flashover Fleksiglas}

Untuk menguji komponen struktur yang digunakan (fleksiglas, dan pralon) dilakukan uji tegangan dadal dan flashover. Karena komponen utama untuk insulasi tegangan tinggi yang terbanyak adalah fleksiglas, maka komponen struktur ini saja yang dilakukan percobaan. Untuk pralon bentuk tabung pengujiannya agak susah, sehingga tidak dilakukan pengujian. Dalam percobaan ini berbagai tebal fleksiglas bentuk lempeng kotak dan bentuk lempeng bundar dengan ukuran yang memenuhi standar uji IEC digunakan untuk diuji tegangan dadal, sedangkan untuk uji flashover digunakan bentuk lempeng bundar. Hasil uji tegangan dadal dan flashover bahan fleksiglas seperti ditunjukkan pada Tabel 1.

Tabel 1. Hasil uji tegangan dadal dan flashover bahan fleksiglas

\begin{tabular}{|c|c|c|}
\hline \multicolumn{3}{|c|}{ Uji tegangan dadal } \\
\hline \multirow{2}{*}{ No } & Dimensi & Tegangan dadal $(\mathrm{kV})$ \\
\cline { 2 - 3 } & Bentuk plat kotak & 180 \\
\hline 1 & $215 \mathrm{~mm} \times 200 \mathrm{~mm} \times 3 \mathrm{~mm}$ & 185 \\
\hline 2 & $215 \mathrm{~mm} \times 200 \mathrm{~mm} \times 5 \mathrm{~mm}$ & 192 \\
\hline & Bentuk plat lingkaran R $=172 \mathrm{~mm}$ & 192 \\
\hline 3 & Teba I $=15 \mathrm{~mm}$ & \\
\hline 4 & Tebal $=20 \mathrm{~mm}$ & \\
\hline
\end{tabular}


Analisis Desain Dan Uji Kinerja Stt-Mbe Basis Trafo (Darsono, Saefurrochman, Rian Suryo Darmawan, Suhartono)

\begin{tabular}{|c|c|c|}
\hline \multicolumn{2}{|c|}{ Uji flashover } & \multirow{2}{*}{ Tegangan flashover $(\mathrm{kV})$} \\
\hline \multirow{2}{*}{ No } & Dimensi & 56 \\
\cline { 2 - 3 } & Bentuk plat lingkaran & 60 \\
\hline 1 & $\Phi 68 \times 3 \mathrm{~mm}$ & 63 \\
\hline 2 & $\Phi 68 \times 5 \mathrm{~mm}$ & 66 \\
\hline 3 & $\Phi 68 \times 10 \mathrm{~mm}$ & 69 \\
\hline 4 & $\Phi 68 \times 15 \mathrm{~mm}$ & \\
\hline 5 & $\Phi 68 \times 20 \mathrm{~mm}$ & \\
\hline
\end{tabular}

Dari Tabel 1 terlihat bahwa untuk tebal fleksiglas yang semakin besar, maka tegangan dadal makin besar. Kenaikan tegangan dadal ini tidak cukup berarti terlihat, kenaikan tegangan dadal untuk tebal $5 \mathrm{~mm}$ dan $20 \mathrm{~mm}$ hanya $7 \mathrm{kV}$. Untuk fleksiglas dengan tebal di atas $15 \mathrm{~mm}$, tegangan dadal konstan sebesar $192 \mathrm{kV}$. Flashover fleksiglas di udara rata-rata adalah $63 \mathrm{kV}$, hal ini bersesuaian dengan hasil yang dilakukan oleh Totok Dermawan ${ }^{(15)}$ pada pengukuran flashover bahan resin yaitu $67,2 \mathrm{kV}$. Flashover ini sangat dipengaruhi oleh kerataan, dan pengotor pada permukaan insulator padat ${ }^{(16)}$. Dari hasil uji bahan konstruksi dapat disimpulkan penggunaan fleksiglas pada trafo diperbolehkan dan telah sesuai dengan standar.

\section{Review Dokumen Desain dan Konstruksi Desain STT}

Dokumen desain STT basis trafo di-review berdasarkan pada standar trafo IEC/SNI (10) , dan handbook trafo $A B B(11)$ (pabrik trafo di Amerika). Fokus review pada bahan yang digunakan dalam pembuatan STT basis trafo baik bahan utama, bahan struktur dan bahan dukung. Berdasarkan hasil review sebagian komponen utama trafo belum mengacu pada standar seperti ditunjukkan pada Tabel 2.

Tabel 2. Hasil komparasi komponen trafo standar dan trafo MBE.

\begin{tabular}{|l|l|l|}
\hline Komponen Trafo & $\begin{array}{l}\text { Oil Filled Transformer Insulation } \\
\text { Handbook, } \\
\text { ABB (IEC 60076-2)(10,11) }\end{array}$ & Trafo MBE \\
\hline Inti besi & Silicon steel & Silicon steel \\
\hline Belitan (coil winding) & Varnish insulation Cu wire & Varnish insulation Cu wire \\
\hline Lapisan insulasi antar lilitan & Diamond epoxy coated kraft paper & Prespan \\
\hline Insulasi konduktor Cu & Electrical grade kraft paper & $\begin{array}{l}\text { Primer menggunakan kain nilon, } \\
\text { sedangkan sekunder tidak pakai. }\end{array}$ \\
\hline Insulasi inti dan belitan & $\begin{array}{l}\text { Paper phenolic tubing and cylinder, } \\
\text { NEMA Grade-20 } \\
\text { Convolute wound glass epoxy tubing and } \\
\text { cylinder, NEMA Grade-10 }\end{array}$ & Pralon \\
\hline Insulasi penguat inti & Glass epoxy laminate,NEMA G-10 & Baut metal \\
\hline Winding bobbin (koker) & $\begin{array}{l}\text { Paper phenolic laminate,NEMA } \\
\text { Grade-10 }\end{array}$ & Pralon \\
\hline $\begin{array}{l}\text { Layer insulation tape (penguat } \\
\text { antara lapisan insulasi dan lilitan) }\end{array}$ & Intertape 51596 & Kain nilon \\
\hline Clamping & High density pressboard material & Baut metal \\
\hline Bahan dukung struktur & Fleksiglas & Pralon dan fleksiglas \\
\hline Oli trafo & Silicon oil & Diala B \\
\hline
\end{tabular}

Dari Tabel 3 terlihat bahwa komponen utama trafo belum memenuhi standar desain, misalnya lapisan insulasi antar lilitan untuk trafo MBE menggunakan prespan yang seharusnya menggunakan diamond epoxy coated kraft paper. Prespan baik untuk trafo insulasi udara, namun tidak cocok untuk insulasi oli karena prespan tidak bisa menyatu dengan oli. Hal yang perlu diperhatikan lainnya ialah insulasi penguat inti dan koker yang seharusnya menggunakan Glass epoxy laminate, NEMA G-10 dan Paper phenolic laminate, NEMA Grade-10. Pada trafo MBE insulasi penguat menggunakan baut metal dan koker menggunakan pralon yang jelas tidak memenuhi standar desain untuk trafo oli Dari review dokumen desain STT-MBE basis oli trafo dapat disimpulkan bahwa sebagian besar komponen bahan STT belum menggunakan standar. 


\section{Simulasi Desain Trafo Menggunakan VIZIMAG}

Dua model simulasi dilakukan dalam menganalisis trafo MBE ini. Pertama menggunakan program Vizimag yaitu suatu program desain trafo berdasarkan metode FEM (Finite Element Method). Berdasarkan parameter desain yang ada yaitu dimensi penampang inti $14 \mathrm{~cm} \times 54 \mathrm{~cm}$, dimensi koker primer $\Phi=21 \mathrm{~cm}, \mathrm{~h}=50 \mathrm{~cm}$, dimensi koker sekunder $\Phi=40 \mathrm{~cm}, \mathrm{~h}=21,5 \mathrm{~cm}$, jumlah lititan primer 94 lilit, jumlah lilitan sekunder 12000 lilit, tahanan primer $0,3 \mathrm{ohm}$, induktansi primer $1,9 \mathrm{H}$, tahanan sekunder $3600 \mathrm{ohm}$, tahanan beban $120 \mathrm{kilo}$ ohm, dilakukan simulasi untuk mengetahui luaran sekunder trafonya pada frekuensi $50 \mathrm{~Hz}$. Karena trafo MBE desain 3 fase, maka ada tiga susunan trafo dengan masukan fasa listrik RST untuk itu diamati pengaruh masukan listrik pada suatu fasa trafo terhadap dua fasa trafo lainnya. Hasil simulasi menggunakan Vizimag seperti ditunjukkan pada Gambar 6, 7 dan 8, sedangkan Gambar 9 menunjukkan kontur medan magnet dari trafo MBE.

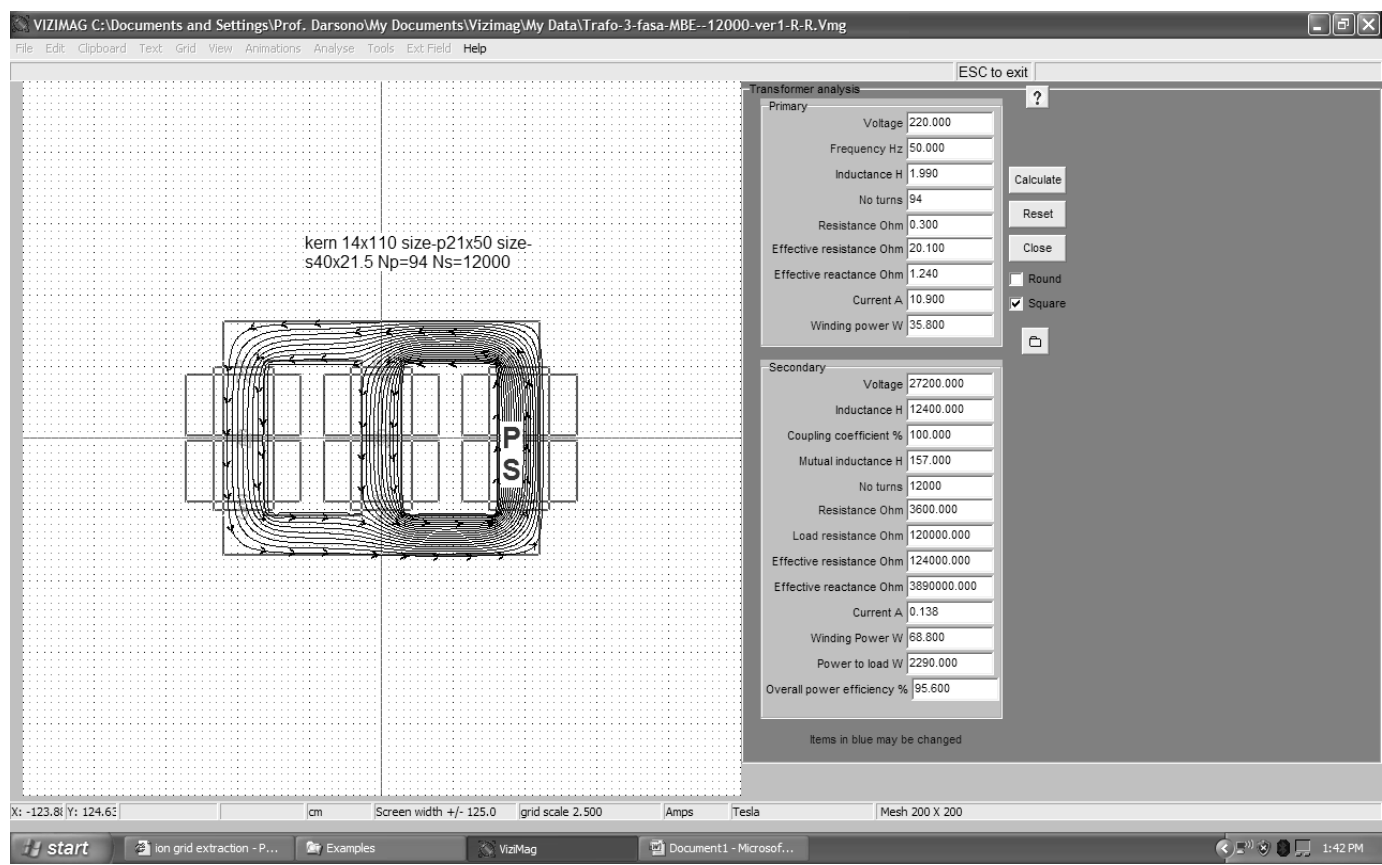

Gambar 6. Simulasi trafo untuk arus datang pada fase R luaran sekunder pada R.

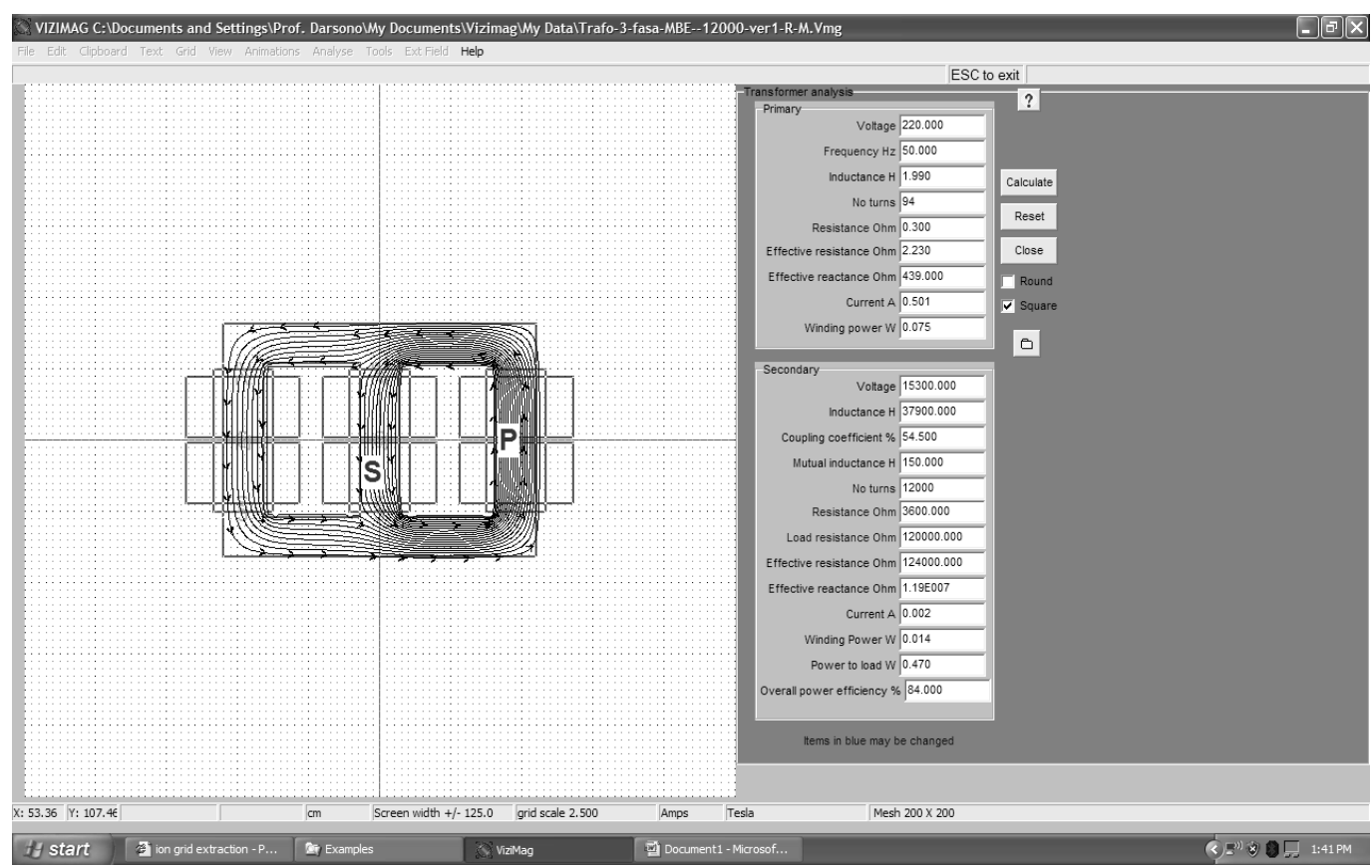

Gambar 7. Simulasi trafo untuk arus datang pada fase R luaran sekunder pada S. 


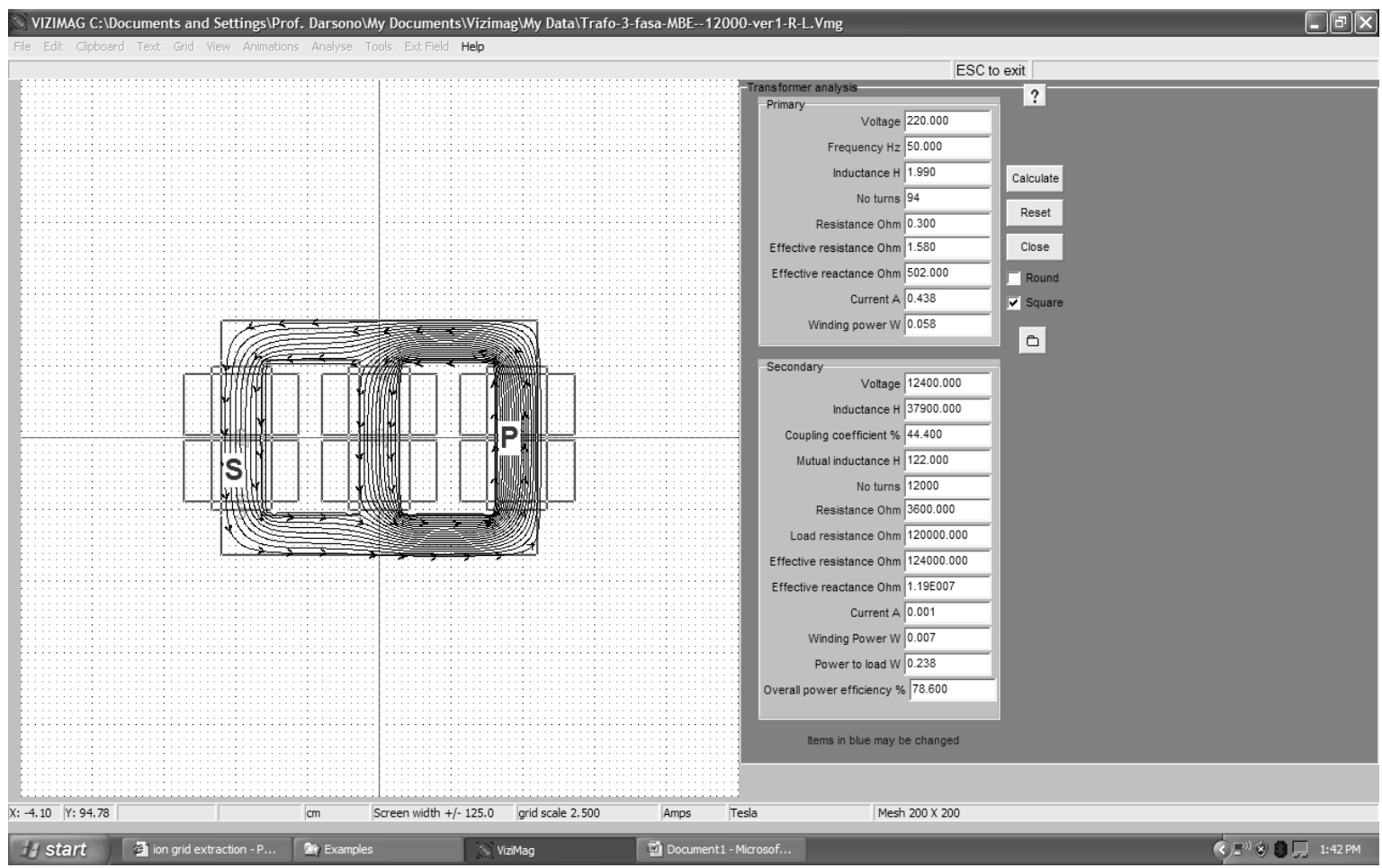

Gambar 8. Simulasi trafo untuk arus datang pada fase R luaran sekunder pada T.

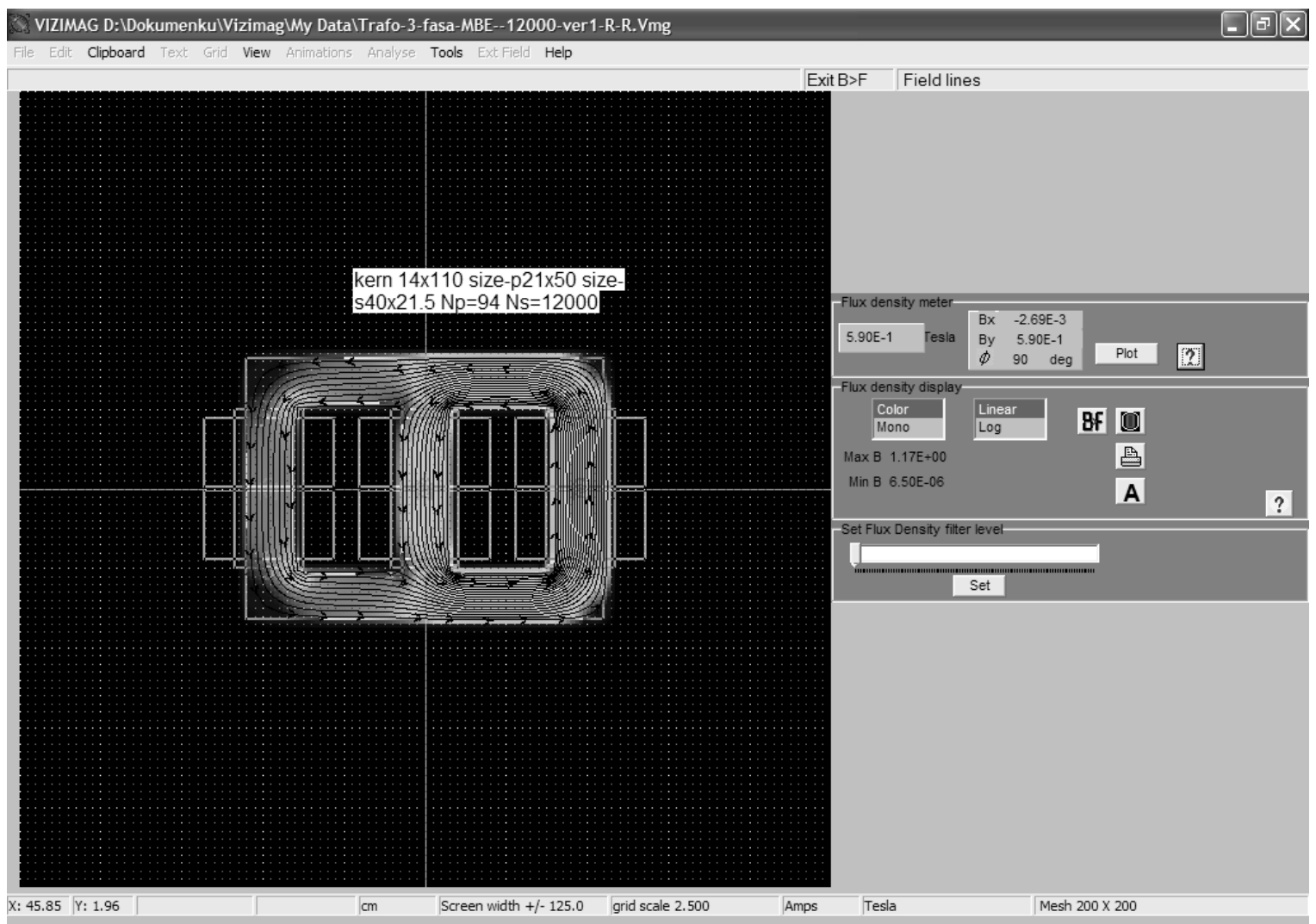

Gambar 9. Simulasi kontur medan magnet dari trafo MBE. 
Ringkasan hasil simulasi seperti ditunjukkan pada Tabel 3. Terlihat pada Tabel 3 bahwa ketika arus datang pada fasa $\mathrm{R}$, maka luaran sekunder sesuai dengan perhitungan trafo secara manual yaitu menghasilkan tegangan sekunder $27 \mathrm{kV}$, namun pada fase $S$ dan T luaran tegangan sekunder menurun menjadi 15,3 kV dan $12,4 \mathrm{kV}$. Demikian halnya dengan koefisien gandengan (coupling coeficient) dan efisiensi dayanya menurun. Hal ini tidak masalah dalam menghasilkan tegangan DC STT, karena luaran masing-masing trafo yang disearahkan memakai dioda, diumpankan ke kapasitor yang disusun secara seri sedangkan waktu peralihan fasa sangat cepat. Besarnya medan magnet yang dibangkitkan pada fase $R$ sebesar 0,58 tesla untuk fase $S$ dan $T$. Besarnya medan magnet tersebut menurun tajam sebagaimana terlihat dari kontur medan magnet pada Gambar 8. Pada fase $\mathrm{R}$ kontur medan magnet sangat rapat, sedangkan untuk fase $\mathrm{R}$ dan $\mathrm{T}$ terlihat kontur medan magnet kurang rapat. Hasil ini menguatkan mengapa koefisien gandengan dan efisiensi daya pada fase $S$ dan T lebih kecil dari R. Dari analisis trafo secara simulasi dapat disimpulkan bahwa prinsip perhitungan analitik pada desain trafo sudah benar. Program simulasi berbasis FEM sekarang ini banyak digunakan dalam mendesain distribusi( ${ }^{(17)}$.

Tabel 3. Ringkasan hasil simulasi anlisis trafo menggunakan Vizimag.

\begin{tabular}{|c|c|c|c|c|c|c|}
\hline \multirow{3}{*}{ No } & \multicolumn{2}{|c|}{$\begin{array}{c}\text { Masukan arus primer trafo pada fase } \\
\mathrm{R}\end{array}$} & \multicolumn{4}{|c|}{ Luaran sekunder trafo } \\
\hline & & & & Fase $\mathrm{R}$ & Fase S & Fase T \\
\hline & Parameter trafo & Nilai & Parameter trafo & Nilai & Nilai & Nilai \\
\hline 1. & Tegangan (V) & 220 & Tegangan (V) & 27200 & 15300 & 12400 \\
\hline 2. & Frekuensi (Hz) & 50 & Induktansi (H) & 12400 & 37900 & 37900 \\
\hline 3. & Induktansi $(\mathrm{H})$ & 1,9 & Koefisien gandengan (\%) & 100 & 54,5 & 44,4 \\
\hline 4. & Jumlah lilitan & 94 & Mutual inductance $(\mathrm{H})$ & 157 & 150 & 122 \\
\hline 5. & Tahanan $(\Omega)$ & 0,3 & Jumlah lilitan & 1200 & 1200 & 1200 \\
\hline 6. & Tahanan efektif $(\Omega)$ & 20,1 & Tahanan $(\Omega)$ & 3500 & 3500 & 3500 \\
\hline 7. & Reaktan efektif $(\Omega)$ & 1,24 & Tahanan beban $(\Omega)$ & $120 \mathrm{k}$ & $120 \mathrm{k}$ & $120 \mathrm{k}$ \\
\hline 8. & $\operatorname{Arus}(A)$ & 10 & Tahanan efektif $(\Omega)$ & $124 \mathrm{k}$ & $124 k$ & $124 k$ \\
\hline 9. & Daya belitan $(\mathrm{W})$ & 35 & Reaktan efektif $(\Omega)$ & $3890 k$ & $11900 k$ & $11900 k$ \\
\hline 10. & & & $\operatorname{Arus}(\mathrm{A})$ & 0,135 & 0,02 & 0,01 \\
\hline 11. & & & Daya belitan $(\mathrm{W})$ & 55 & 0,014 & 0,007 \\
\hline 12. & & & Daya ke beban (W) & 2290 & 0,47 & 0,235 \\
\hline 13. & & & Efisiensi daya total (\%) & 85 & 54 & 35 \\
\hline
\end{tabular}

\section{KESIMPULAN}

Dari hasil review dokumen desain, hasil analisis eksperimen tegangan dadal dan flashover serta dari simulasi analisis trafo dapat disimpulkan bahwa penyebab utama spesifikasi STT-MBE tidak dapat dicapai adalah karena penggunaan oli trafo sebagai insulasi STT yang tidak sesuai standar dan tata letak komponen STT yang menggunakan asumsi insulasi oli STT berfungsi. Dari hasil uji bahan konstruksi dapat disimpulkan bahwa penggunaan fleksiglas pada trafo diperbolehkan dan telah sesuai dengan standar. Dari review dokumen desain STT-MBE basis oli trafo dapat disimpulkan bahwa sebagian (sekitar 40\%) komponen bahan STT belum memenuhi standar. Dari analisis trafo secara simulasi dapat disimpulkan bahwa prinsip perhitungan analitik pada desain trafo sudah benar. Berdasarkan penelitian ini dapat disimpulkan bahwa trafo tidak dapat dioperasikan sesuai spesifikasi teknis, namun dengan perbaikan tata letak komponen STT di dalam bejana oli diharapkan dapat dioperasikan sampai $260 \mathrm{kV}$. 


\section{UCAPAN TERIMA KASIH}

Ucapan terima kasih kepada Sdr. Heri Sudarmanto dan Sumaryadi yang telah membantu dalam kegiatan penelitian ini.

\section{DAFTAR PUSTAKA}

1. S. MACHI, "Radiation Technology for Sustainable Development", Proceeding of INAC, Sao Paolo (2007) 1-5.

2. M.R. CLELAND, et.al., "Applications for Radiation Processing of Materials", Proceeding of the Twelve International Meetings on Radiation Processing, Pergamon, New York Vol.52. (2002).

3. D.R. KERLUKE, S. CHENG, "Electron Beam Processing for Automotive Composite Application", in Proceedings of the 2nd Annual Automotive Composite Conference and Exposition of the Society of Plastic Engineers, Detroit (2002).

4. M. SUHARINI, Vulkanisasi lateks karet alam secara batch dengan iradiasi berkas elektron, PPI Aplikasi radiasi, P3TIR-BATAN (2002).

5. DARSONO, "Peran Teknologi Akselerator Dalam Mendukung Industri" Prosiding PPI Teknologi Akselerator dan Aplikasinya Vol.10, PTAPB-BATAN (2008).

6. DARSONO, "MBE Skala Industri Untuk Produksi Lateks Karet Alam Iradiasi: Manufaktur, Pangsa Pasar dan Teknoekonomi LKAl", Prosiding PPI Teknologi Akselerator dan Aplikasinya, PTAPB-BATAN Vol.11 (2009).

7. H.M. RYAN, High Voltage Engineering and Testing, IEE Vacation Schools (2008).

8. DJASIMAN, DARSONO, dan SUPRAPTO, "Rancangan dan Simulasi Sumber Tegangan Tinggi Jenis Transformator", ", Prosiding PPI Teknologi Akselerator dan Aplikasinya, P3TM-BATAN Vol.7 (2005).

9. DARSONO, E. PRIYONO, R. SAPTAAJI, SUKIDI, SUKARYONO, A. T. PURWANTO, SAEFUROHMAN,TAUFIK, SUHARTONO, A. DWIATMOJO, DAN SUTADI, "Pengembangan dan Rancangbangun Mesin Berkas Elektron", LAPORAN TEKNIS Bidang Teknologi Akselerator dan Fisika Nuklir, PTAPB_BATAN, Yogyakarta (2010).

10. Transformer Tenaga, SNI 04-6954-2003, ICS 29.180 Badan Standardisasi Nasional.

11. Transformer Insulation Handbook, download from http://thegundcompany.com/ files/index.cfm?pdfpath= Transformer\%20Dry\%20Type\%20Handbook1.pdf, (2010).

12. Vizimag 3.18 Free Trial - Simple to use electromagnetic simulation, download from http://www.softpedia.com/get/Science-CAD/Vizimag.shtml, (2011).

13. R. SARATHI, A.J. REID, M.D. JUDD, Electric Power Systems Research, Volume 78, Issue 11, (2008) 1819-1825.

14. P. KOPČANSKÝ, L. TOMČO, K. MARTON, M. KONERACKÁ, M. TIMKO, I. POTOČOVÁ, Journal of Magnetism and Magnetic Materials, Volume 289, (2005) 415-41.

15. T. DERMAWAN, Desain dan Analisis Feedthrough Tegangan Tinggi Mesin Berkas Elektron $300 \mathrm{keV/20}$ $m A$, Tesis S-2, Program Pasca Sarjana, Fakultas Teknik, UGM, (2011).

16. M. T. GENÇOĞLU, and M. CEBECI, Electric Power Systems Research, Volume 78, Issue 11, (2008) 1914-1921.

17. C. HERNÁNDEZ, M.A. ARJ, Finite Elements in Analysis and Design, Volume 43, Issue 8, (2007) 659-665. 